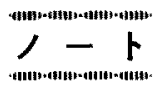

\title{
ポリスチレン中で結晶化した1,4-ジアミノ アントラキノンの球晶構造
}

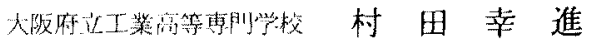

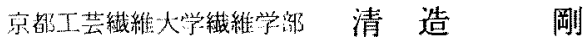

\section{SPHERULITIC STRUCTURES OF 1,4-DIAMINOANTHRAQUNONE CRYSTALLIZED IN POLYSTYRENE}

\author{
By Yukinobu Murata ${ }^{* 1}$ and Tsuyoshi Kiyotsukuri*2 \\ *1 (Osaka Prefectural Technical College, 26-12, Saiwai-cho, \\ Neyagawa, Japan) \\ *2 (Faculty of Textile Science, Kyoto University of Industrial Arts \\ and Textile Fibers, Matsugasaki, Sakyo-ku, Kyoto, Japan)
}

The polystyrene films containing 1,4-diaminoanthraquinone dye were examined with an optical microscope during heating and cooling at constant rates. Spherulitic structures were observed which were composed of needle-like crystallites of the dye in the cooling process. Size of these spherulites increased with increasing dye content and with decreasing cooling rate. Size of crystallites formed in cooling process was larger than that formed in heating process.

(Received February 28, 1983)

\section{1. 緒言}

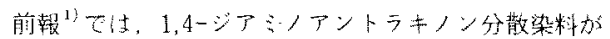

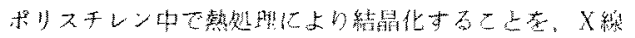

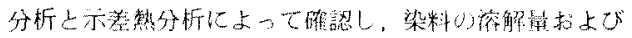

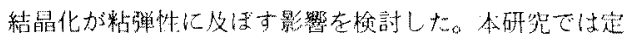

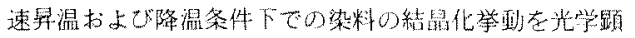

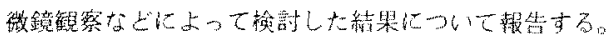

\section{2. 跙 法}

\section{1 染料混入試料の調製}

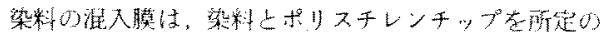
割合で湿合し， $280^{\circ}$ Cでホットプレスして得た。1国り プレスでは湿合状態が不均一であったので，膜を粉研し

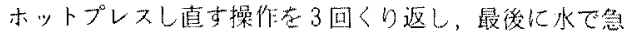

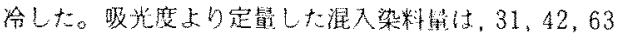
执よび $73 \mathrm{mg} / \mathrm{g}$ filmです。

\section{2 結晶化条件}

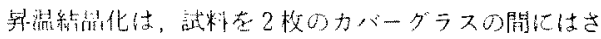

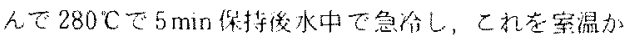

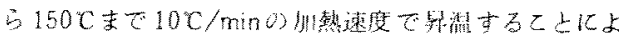

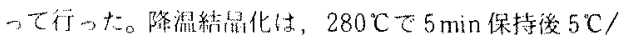

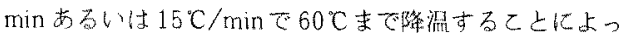

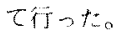

\section{3 光学显微鏡観察}

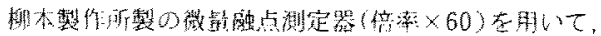

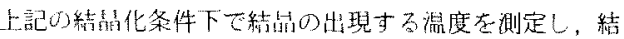

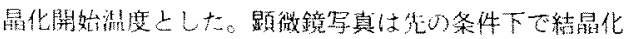

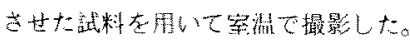

\section{$2.4 \mathrm{X}$ 線分析法}

既報 ${ }^{2)}$ ゆ2.5 亿記しだ法によった。

2.5 示爇分析法

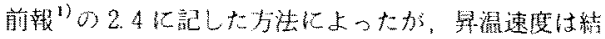

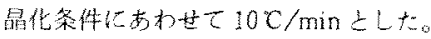



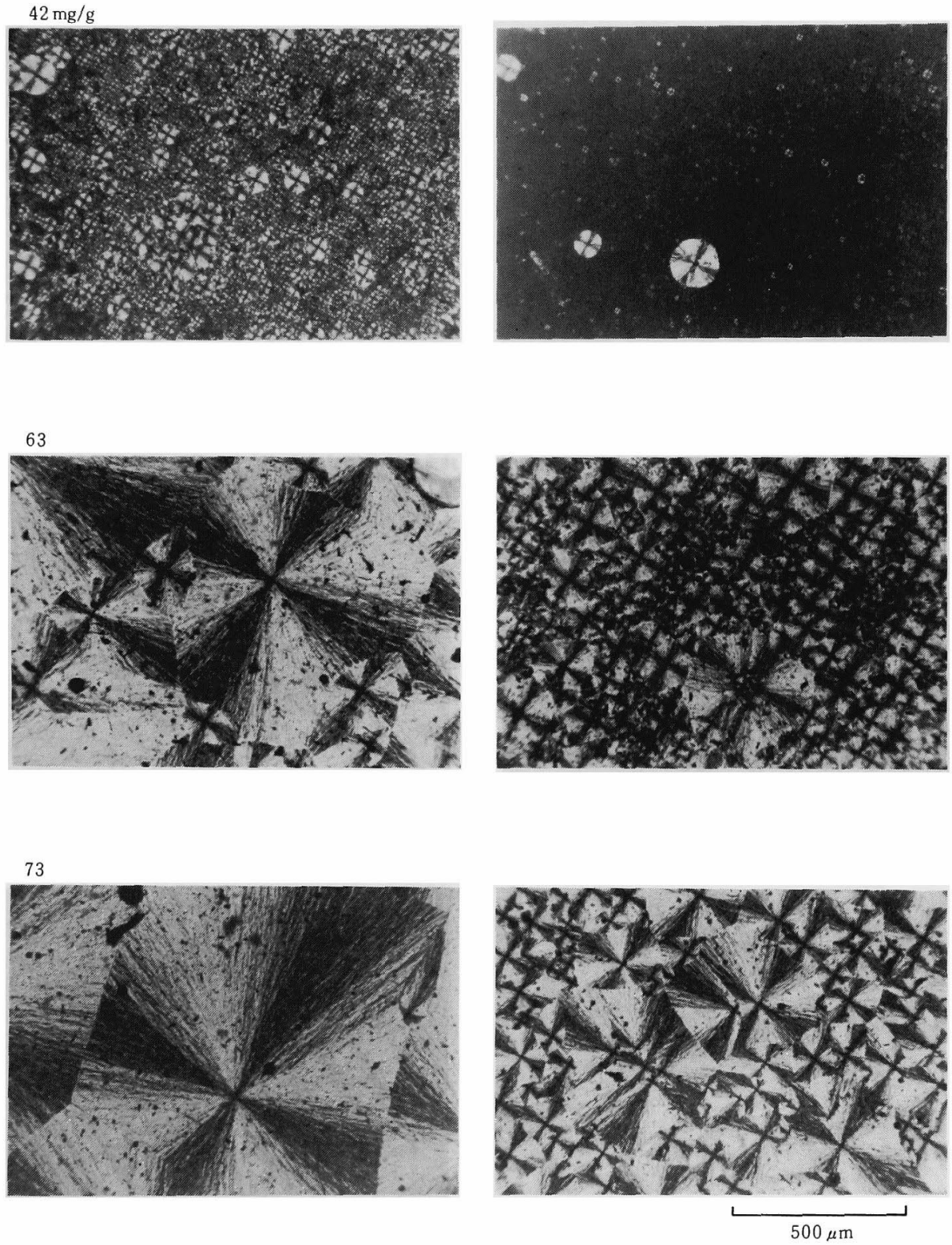

Fig. 1. Polarized micrographs of samples with different dye content cooled from $280^{\circ} \mathrm{C}$ to $60^{\circ} \mathrm{C}$ at a rate of $5^{\circ} \mathrm{C} / \mathrm{min}$ (left) and a rate of $15^{\circ} \mathrm{C} / \mathrm{min}$ (right). 
$31 \mathrm{mg} / \mathrm{g}$

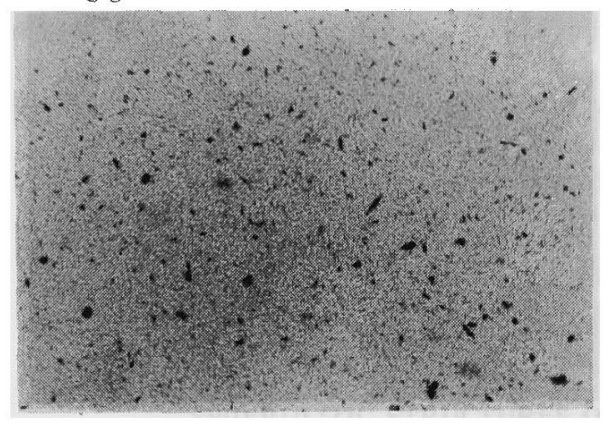

42

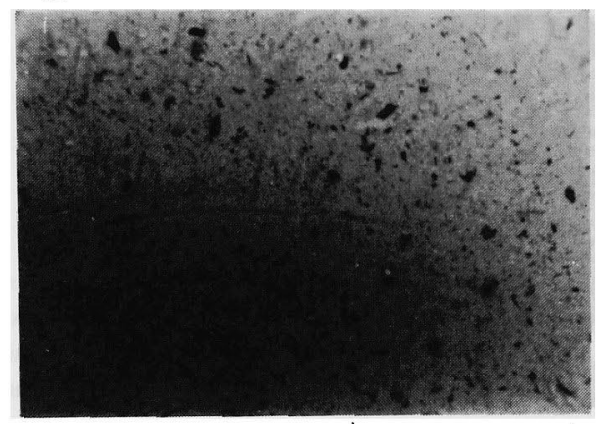

63

$500 \mu \mathrm{m}$
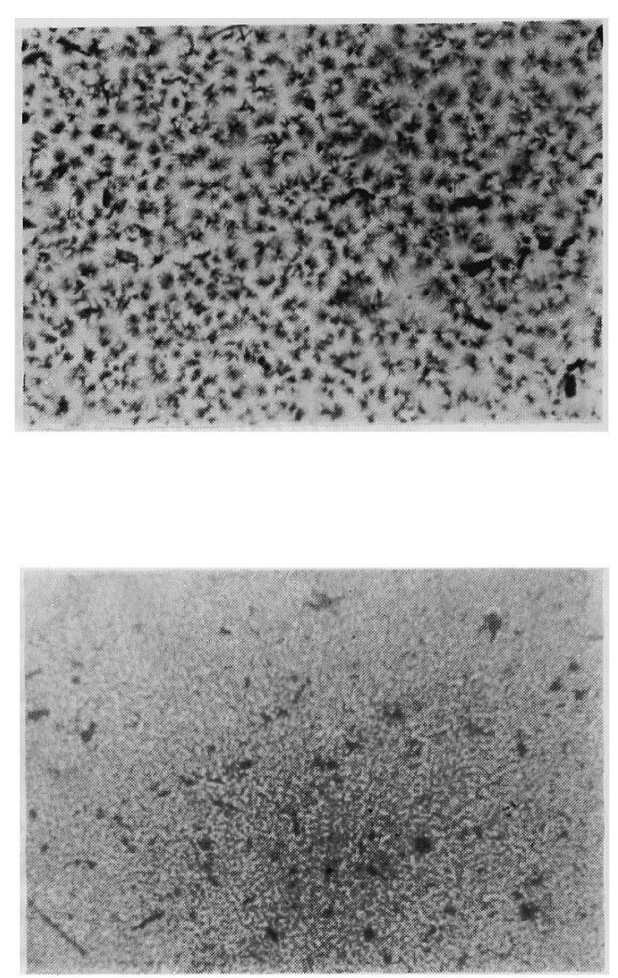

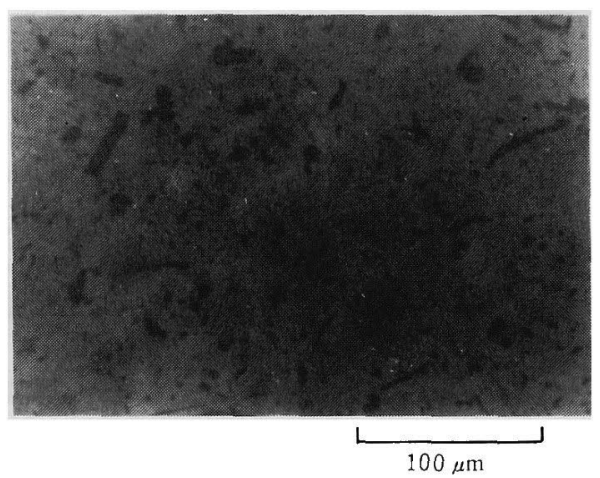

Fig. 2. Micrographs of samples with different dye content heated from room temperature to $150^{\circ} \mathrm{C}$ at a rate of $10^{\circ} \mathrm{C} / \mathrm{min}$. 


\section{3. 結果と考察}

図1に降温結晶化試料の确光顕微鏡写真を示す。高染 料潧度の試料では，中心加ら放射状に発生した針状の碠 䊅霜によって構成されている球晶状結晶成長か観察され る。球晶の形成は俟分子化合物でも観察されているが ポリスチレンの媒質中で染料が結晶化した林試料の場合 にす，てのような球晶形態をとることは注目されよう。 球晶が形成されるためには，粘晶の成長速度が結晶面に よって著しく異なることが条件の1つとなる゙，。本研觉 の場合にはポリスチレン媒質中での結晶成長なので，染 料分子の結鼠化のための移釛はポリスチレ銷によって 判制されるであるう。このためにポリスチレン銷の閒陌 をぬった結晶の成長は，抑制老うけて球晶的形態をしっ たものと思加る。な捛，上とろどころに見られる黑い 斑点は未溶解染料乞思加れる。图1では，降温速度加幄 いほうが，また染料舆が多いほうが大きな球晶が見られ る。図2 亿鼠温結晶化試料の影微譱写真を示す。とれら の試料の球昆の大きさは，园1の降温時に顴察された球 鼠上りるはるか心小さい。球晶は核の発生とその成長に よって形成され，球晶同士がふらつかることによって成長 は停止する。図 2 の昇温結昆化試料では，核発生速度加 成長速度より屯速く，々のた好多数の核が発生し， その結果球鼠が大き成長できなかったもの上推定され 万。

図 3 に顕微鏡観察によっで得た結晶化開始温度 $\left(T_{c}\right)$ の 染料量依存性を示す。昇温結晶化では，球晶の大きさか 小さすぎて染料の結鼠化が明瞭には観祭できなかったの

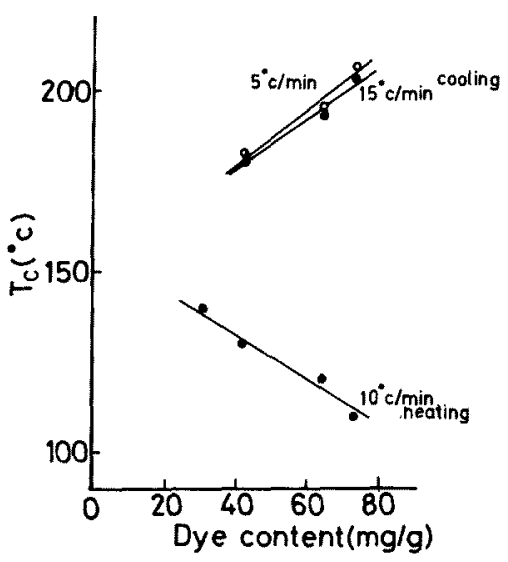

Fig. 3. Variation of crystallization temperature with dye content in cooling process $\left(5^{\circ} \mathrm{C} / \mathrm{min}\right.$ and $\left.15^{\circ} \mathrm{C} / \mathrm{min}\right)$ and heating process $\left(10^{\circ} \mathrm{C} / \mathrm{min}\right)$.
で，視野が暗くなった温度を $T_{c}$ とした。 $T_{\mathrm{c}}$ は染料量の 減少とともに，昇温時には上㫧し，降温時には降下して いる。これは，染料量が少ないほど染料が集合するのに 上り時闌がかかるために，その間に温度がより上昇(早 温㭙)あるいは降下(降温洔)したとよによると考えられ 万。

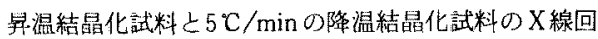
折强度曲線を园 4 亿示す。 $2 \theta=11.2^{\circ}$ の染料の結晶の回折 ピークの半価幅を表 1 に示す。昇温結晶化では染料量が 增打すると半価幅が增大して微結鼠の大きさが小さくな っており，乙れは図2で球晶の大きさが染料量の增加で 小さくなることと対応している。いっばう降温結晶化試 料の铛結晶は开湜結晶化試料のそ机よりも大きいが，染 料量によって相違しない。これは大きな球晶が生じる条 件では微結晶も十分成長して飽和值になったとをによる よ推定される。

染料量 $73 \mathrm{mg} / \mathrm{g}$ の試料についてそれぞれ $5 \mathrm{C} / \mathrm{min} る$
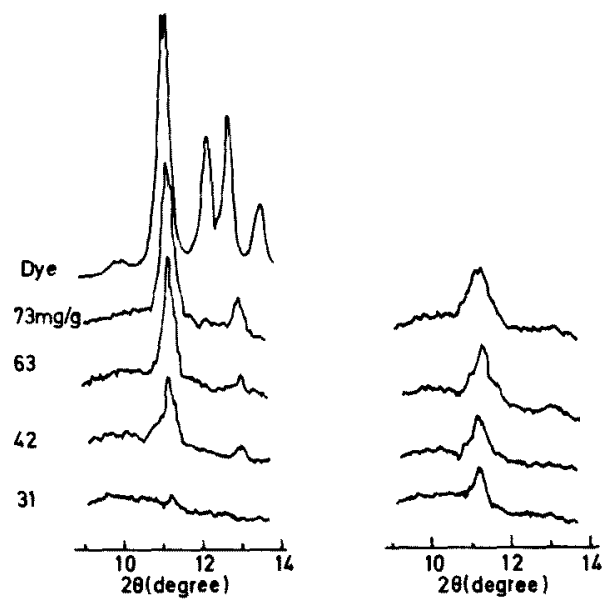

Fig. 4. X-ray diffractograms for samples cooled at a rate of $5^{\circ} \mathrm{C} / \mathrm{min}$ (left) and heated at a rate of $10^{\circ} \mathrm{C} / \mathrm{min}$ (right).

Table 1. X-ray half-width for samples cooled at a rate of $5^{\circ} \mathrm{C} / \mathrm{min}$ (cooling) and heated at a rate of $10^{\circ} \mathrm{C} / \mathrm{min}$ (heating).

\begin{tabular}{|c|c|c|}
\hline \multirow{2}{*}{$\begin{array}{l}\text { Dye content } \\
(\mathrm{mg} / \mathrm{g})\end{array}$} & \multicolumn{2}{|c|}{$\begin{array}{l}\text { Half-width } \\
\text { (degree) }\end{array}$} \\
\hline & cooling & heating \\
\hline 31 & - & 0.35 \\
\hline 42 & 0.30 & 0.46 \\
\hline 63 & 0.30 & 0.47 \\
\hline 73 & 0.30 & 0.55 \\
\hline
\end{tabular}




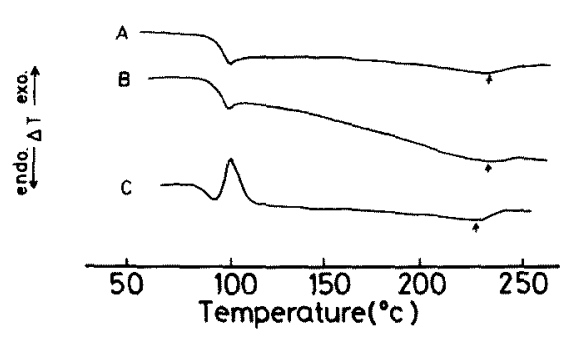

Fig. 5. DTA curves for samples with the dye content of $73 \mathrm{mg} / \mathrm{g}$. A, measured after cooling at $5^{\circ} \mathrm{C} / \mathrm{min} ; \mathrm{B}$, measured after cooling at $15^{\circ} \mathrm{C} / \mathrm{min}$; $\mathrm{C}$, measured after quenching in water from $280^{\circ} \mathrm{C}$.
いは $15^{\circ} \mathrm{C} / \mathrm{min} て ゙$ 降温して結晶化ざせたもの(それぞれA およびB) および溶融状態から水中に急冷したもの(C) の示差熱分析曲線を园5亿示す。試料の結晶の触点は図 中に矢印で示した。降温結晶化試料(Aおよ゙B)の融点 はCよりも高い。Cでは100C付近に発熱ピークが出現 しており，乙れは測定時に染料が結鼠化したしとを示す が，この上うな舁溻結晶化による微結鼠の融点が降濕結 鼠化のそれよりも低いてとは，㣪者のはうが微結鼠が大 きいととを意味しており，表 1 で降温結晶化試料の微結 鼠が眾湿結晶化試料のそれよりむ大きいX線による結果 とよく対応している。

\section{文献}

1）村田幸進，清造 㧩；織学誌，39，T-84（1983）

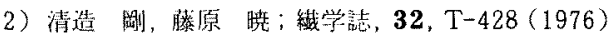

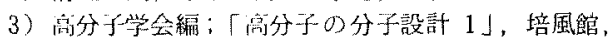
p. 194 (1972) 